\title{
Results-Based Financing in Mozambique's Central Medical Store: A Review After 1 Year
}

\author{
Cary Spisak, ${ }^{a}$ Lindsay Morgan, ${ }^{b}$ Rena Eichler, ${ }^{c}$ James Rosen, ${ }^{d}$ Brian Serumaga, ${ }^{a}$ Angela Wang ${ }^{a}$
}

The RBF scheme, which paid incentives for verified results, steadily improved the CMS's performance over 1 year, particularly for supply and distribution planning. Key apparent success factors:

1) The CMS had full discretion over how to spend the funds.

2) Payment was shared with and dependent on all staff, which encouraged teamwork.

3) Performance indicators were challenging yet achievable.

4) The quarterly payment cycle was frequent enough to be motivating.

Recommendations for future programs: focus on both quality and quantity indicators; strengthen results verification processes; and work toward institutionalizing the approach.

\section{ABSTRACT}

Background: Public health commodity supply chains are typically weak in low-income countries, partly because they have many disparate yet interdependent functions and components. Approaches to strengthening supply chains in such settings have often fallen short-they address technical weaknesses, but not the incentives that motivate staff to perform better.

Methods: We reviewed the first year of a results-based financing (RBF) program in Mozambique, which began in January 2013. The program aimed to improve the performance of the central medical store-Central de Medicamentos e Artigos Medicos (CMAM) - by realigning incentives. We completed in-depth interviews and focus group discussions with 33 key informants, including representatives from CMAM and donor agencies, and collected quantitative data on performance measures and use of funds.

Implementation: The RBF agreement linked CMAM performance payments to quarterly results on 5 performance indicators related to supply planning, distribution planning, and warehouse management. RBF is predicated on the theory that a combination of carrot and stick-i.e., shared financial incentives, plus increased accountability for results - will spur changes in behavior. Important design elements: (1) indicators were measured against quarterly targets, and payments were made only for indicators that met those targets; (2) targets were set based on documented performance, at levels that could be reasonably attained, yet pushed for improvement; (3) payment was shared with and dependent on all staff, encouraging teamwork and collaboration; (4) results were validated by verifiable data sources; and (5) CMAM had discretion over how to use the funds. Findings: We found that CMAM's performance continually improved over baseline and that CMAM achieved many of its performance targets, for example, timely submission of quarterly supply and distribution planning reports. Warehouse indicators, such as inventory management and order fulfillment, proved more challenging but were nonetheless positive. By linking payments to periodic verified results, and giving CMAM discretion over how to spend the funds, the RBF agreement motivated the workforce; focused attention on results; strengthened data collection; encouraged teamwork and innovation; and ultimately strengthened the central supply chain.

Conclusion: Policy makers and program managers can use performance incentives to catalyze and leverage existing investments. To further strengthen the approach, such incentive programs can shift attention from quantity to quality indicators, improve verification processes, and aim to institutionalize the approach.

\footnotetext{
a USAID I DELIVER PROJECT, John Snow, Inc., Washington, DC, USA.

${ }^{b}$ Health Finance and Governance Project, Bethesda, MD, USA.

'Health Finance and Governance Project, Broad Branch Associates, Washington, DC, USA.

¿USAID I DELIVER PROJECT, Avenir Health, Glastonbury, CT, USA.

Correspondence to Cary Spisak (cary_spisak@jsi.com).
}

\section{BACKGROUND}

$\mathrm{n}$ the decades following the end of a prolonged civil war, Mozambique made important strides in health, including a decrease in the under-5 mortality rate, from 219 per 1,000 live births in 1990 to 97 per 1,000 in 


Public-sector
supply chains in
many low-income
countries suffer
from poor
performance,
often due to
misaligned
incentives.

2011. However, serious gaps have persisted. The maternal mortality ratio remains high, at 480 deaths per 100,000 live births $(2013)^{2}$; the prevalence of modern contraceptives is only $7 \%$ in rural areas $(2011)^{3}$; and both HIV and malaria are hyperendemic - the national HIV prevalence is $10.6 \%$ (2014 estimates). ${ }^{4}$

One of the underlying challenges is the poor performance of the public health supply chain. The Central Medical Store-Central de Medicamentos e Artigos Medicos (CMAM) - is responsible for managing the procurement, importation, centrallevel warehousing, and distribution of medicines and commodities used by the public health system to provinces. Over the years, reductions to its administrative autonomy and to access to resources created operational challenges that hindered the organization's ability to respond both to emergencies and to routine needs. An assessment of medicines procurement and the supply chain management system, undertaken in February 2011, ${ }^{5}$ found multiple shortcomings:

- Poor information accuracy and flow between the central, provincial, and district levels

- Ad hoc distribution of medicines from provinces to districts and health facilities

- Fragmented management responsibility

\section{- Inflexible financing}

Supply chains are foundational for any health system, encompassing "the planning and management of all activities involved in sourcing and procurement $\ldots$ and all logistics management activities. [This] also includes coordination and collaboration with ... suppliers, intermediaries, third-party service providers, and customers." ${ }^{6}$

For health supply chains to work, many actors in different locations must do their part.
For health supply chains to work-for the right goods to be received and delivered in the right quantities, in good condition, to the right place, at the right time, for the right cost-many actors working in different locations, with different responsibilities, need to be motivated to do their part. And they must be held accountable. These actorsfrom central-level planners and procurement specialists, to regional warehouse and transportation teams, to local storekeepers and service providersdepend on each other for timely and accurate information and a reliable supply of health commodities. One break in the chain, one delay, can have repercussions throughout the system, ultimately affecting whether families can access lifesaving medicines and commodities.
Public-sector supply chains in many lowincome countries suffer from poor performance. A key contributor is the often misaligned incentives at work in highly centralized public-sector bureaucracies, where the responsibility for essential, but disparate, tasks are assigned to individuals who may have weak incentives to perform well or in concert with one another. ${ }^{7}$ Misaligned incentives may be found throughout the supply chain and may include low compensation for staff paid irrespective of performance; poor communication, coordination, and accountability arrangements; or insufficient resources for management to invest in the necessary infrastructure and other investments to support the long-term success.

In Mozambique, underperformance at CMAM has negatively affected the functioning of the supply chain as a whole, resulting in inaccurate information about stock levels and expiries, as well as delayed and inefficient distribution. Many strategies have been tried to improve the performance of CMAM. A warehouse management system was introduced, for example, providing tools to better control and manage stock and data. A monitoring and evaluation (M\&E) framework was developed and a dedicated M\&E unit created within CMAM to routinely track performance. And an electronic payment systeme-SISTAFE—has enabled CMAM to pay some suppliers and manage limited funds, independent of the Ministry of Health's Department of Administration and Finance (DAF).

Donor financial and technical support has been significant. CMAM receives technical assistance and commodities from the US Government (USG); operational funding and commodities from the World Bank; and commodities from the Global Fund to Fight AIDS, Tuberculosis and Malaria (The Global Fund). The USG alone invests an average of US\$10-15 million annually for technical assistance to CMAM.

Additionally, the Ministry of Health and its partners have developed supportive action plans and policies, such as the Supply Chain Logistic Plan of Action $2012^{8}$ and the Pharmaceutical Logistics Strategic Plan 2013, ${ }^{9}$ which includes a performance indicator and monitoring framework. These plans identify several goals:

- Improved quality and timeliness of information flow between districts, provinces, and CMAM, and better use of this information for planning and procurement 
- Better planning for distribution from provincial warehouses to the districts

- Stronger supervision and internal audit of province/district stores by CMAM

Despite these improvements, CMAM has lacked data to demonstrate improved supply chain outcomes, and stakeholders in Maputo believed that CMAM's performance was not improving as expected.

In this context, result-based financing (RBF) was proposed, both to realign incentives and to catalyze other investments in CMAM. RBF refers to "any program that rewards the delivery of one or more outputs or outcomes by one or more incentives, financial or otherwise, upon verification that the agreed-upon result has actually been delivered." ${ }^{10}$ RBF programs vary widely, but most address poor performance by providing performance payments for verified results and some measure of autonomy over how to spend the incentives.

The vast majority of RBF programs in lowand middle-income countries provide incentives either to patients, to encourage and enable them to seek and access health services, or to health care providers, to increase the quantity and improve the quality of the services they provide. Where RBF is being tried, experience suggests it can have an impact on health and may strengthen the health system in the process. ${ }^{12}$

Although use of performance incentives is common in high-income country supply chains, until recently, few-if any-RBF programs directly targeted public health supply chains in low-income countries. Momentum is increasing, however, to develop RBF approaches that specifically target these health supply chains. By linking incentives with verified results, RBF is increasingly viewed as one way to motivate the supply chain workforce; focus attention on-and provide demonstrable evidence of-measurable results; strengthen data collection and information systems; and, ultimately, strengthen the supply chain and improve health.

This paper reports on how Mozambique used RBF to improve the performance of CMAM and the supply chain. RBF was incorporated into a fixed amount reimbursement agreement (FARA or FAR agreement), a type of assistance from the United States Agency for International Development (USAID) that disburses a fixed amount of funds based on outputs rather than inputs. FARAs closely align with RBF approaches: the agreements condition payments upon the achievement of specific, time-bound, target-based, verified results.
Mozambique's supply chain FARA was the first time RBF had been used in the public health supply chain to drive improvements in operational performance.

The agreement was designed in coordination with the Ministry of Health-Ministerio da Saude, or MISAU-and its key partners: USAID, the World Bank, and The Global Fund. All parties had an interest in leveraging past investments in and assistance to CMAM, as well as in creating synergies with planned and future initiatives. For example, a World Bank RBF project will aim to strengthen the supply chain at the provincial level, thus complementing USAID's investments in strengthening central medical store performance.

The FARA was signed on December 6, 2012, between USAID and the Directorate of Planning and Coordination (DPC) within MISAU, with a l-year performance period beginning January 2013. (The DPC coordinates MISAU's national directorates. At the time of this review, CMAM was positioned under the National Directorate for Medical Assistance-Direç̧ão Nacional de Assistência Médica, or DNAM. In April 2014, CMAM was promoted to the level of national directorate.)

\section{EVALUATION METHODS}

To understand what drove performance improvements at CMAM under the FARA, in March 2014 (14 months after the performance period began), the authors-a representative from the USAID | DELIVER PROJECT and a representative from USAID's Health Finance and Governance (HFG) project-completed in-depth interviews and focus group discussions with 33 key informants in Maputo. Using a semi-structured interview guide, the consultants met with program stakeholders, including representatives from CMAM, USAID and other donor agencies-the World Bank, UK's Department for International Development (DFID), and the United Nations Population Fund (UNFPA) - as well as mid- and lower-level staff at CMAM.

Where possible, basic quantitative data points related to performance measures of supply and distribution planning and warehouse operations, as well as use of funds, were collected.

Results-based financing is predicated on the theory that financial incentives will spur changes in behavior. The authors hypothesized that performance incentives would improve supply chain performance through 3 principal pathways:

\section{Results-based financing (RBF) was introduced in Mozambique to improve the performance of the public health supply chain.}


1. Improved staff motivation-leading to better attendance and job performance

\section{Improved collaboration and cooperation}

3. Increased investment in supply chain infrastructure

In analyzing data, we sought to understand the extent to which respondent narratives matched our hypotheses, the extent to which they differed, and whether they differed depending on the respondent's position in the organization or the sectors in which they worked. The interview guide, as a flexible qualitative instrument, was modified as new themes were uncovered.

\section{THE INTERVENTION: RBF FOR THE PUBLIC HEALTH SUPPLY CHAIN IN MOZAMBIQUE}

Most RBF agreements include several key elements:

- An incentive recipient, who stands to receive a financial incentive contingent upon verified results

- Performance indicators and targets that must be reached

- A process to verify results at a certain frequency (e.g., each quarter, twice a year, annually)

- The structure of the payment itself

\section{Incentive Recipient: CMAM - the Central Medical Store}

The incentive recipient in the FARA was CMAM. The objective of the agreement was to improve the performance of the central medical store, and thereby spark improvements in the supply chain generally for all key commodities in Mozambique.

\section{Performance Indicators and Targets}

The FARA specified 5 performance indicators (Table), which focused on 3 priority areas or sectors-supply planning, distribution planning, and warehouse operations. Each sector had a

Performance targets were not too easy nor too hard to achieve. history of underperformance at CMAM and, if improved, could facilitate continuous improvements within the sectors as well as improvements in lower levels of the supply chain.

The supply planning sector used planning and quantification reports to inform annual procurement and funding decisions, as well as periodic inventory replenishment activities. Each quarter, the Medicines Working Group-Grupo de Trabalho de Medicamentos (GTM) - convened meetings for each of its product category "subgroups" to agree on quarterly commodity supply plans or annual quantification plan reports. The supply planning performance indicator required these quarterly reports to be submitted on time, and according to specific quality criteria. Eight product category subgroups were measured by this indicator: HIV/AIDS, malaria, tuberculosis, essential medicines, laboratory, reproductive health, vaccines, and medical materials.

Similarly, distribution planning is an important step in CMAM's order fulfillment cycle-when orders are validated and inventory allocated, and if necessary, rationed. Timely distribution planning could enable more timely delivery of orders to provincial and district levels, thereby reducing the risk of stock-outs at lower levels.

Warehouse indicators measured the accuracy of filling quarterly orders ("order pick and pack" accuracy); the time required to dispatch quarterly orders to recipients; and the ongoing maintenance of accurate physical inventory against inventory records.

The indicators chosen for the FARA were considered core supply chain performance indicators: areas on which broader supply chain performance improvements would rely. For example, measuring and improving inventory accuracy is necessary before other inventory- and financerelated data-such as product leakage or expiry rates-can be measured.

Only indicators that could be routinely measured and verified were chosen, and data sources and reporting mechanisms were validated or created for each indicator. Additionally, all of the indicators were defined with targets to be measured on a quarterly basis. This ensured that performance data were being collected and monitored on a regular basis, facilitating periodic evaluation and adjustment, and that staff were continuously working toward a near-term goal. This structure also aligned with the common commercial-sector practice of quarterly reporting of business results.

The targets themselves were set based on baseline performance and at levels that presented a reasonable challenge while nonetheless being within CMAM's control to achieve. In other words, the targets were not too easy, nor too hard. For 2 indicators, "order pick and pack accuracy" and "inventory accuracy," the quarterly targets became increasingly more difficult each subsequent quarter. 
TABLE. Indicators, Targets, and Payment Amounts for the Mozambique Fixed Amount Reimbursement Agreement (FARA)

\begin{tabular}{|c|c|c|}
\hline Functional Area & $\begin{array}{c}\text { Milestones to Be Completed Each Quarter of Calendar Year } 2013 \\
\text { USAID will reimburse CMAM the value specified as USAID's contribution, } \\
\text { as noted below, upon certification by DPC and approval and acceptance } \\
\text { as certified by USAID of the following milestones at the end of each } \\
\text { quarter of calendar year } 2013 .^{a}\end{array}$ & $\begin{array}{l}\text { USAID's Contribution } \\
\text { (Fixed Reimbursement } \\
\text { Amount) per Quarter }\end{array}$ \\
\hline $\begin{array}{l}\text { Supply planning/ } \\
\text { forecasting }\end{array}$ & $\begin{array}{l}\text { (a) Annual quantification plan that meets } 3 \text { predetermined criteria, for each } \\
\text { product group, or (b) Quarterly updated supply plan that meets } 3 \text { predetermined } \\
\text { criteria, for each product group }\end{array}$ & $\$ 25,000$ \\
\hline $\begin{array}{l}\text { Distribution } \\
\text { planning }\end{array}$ & $\begin{array}{l}\text { Order cycle time for distribution planning is } 15 \text { calendar days or less for via } \\
\text { Clássica orders to the } 18 \text { central }+ \text { provincial clients }\end{array}$ & $\$ 25,000$ \\
\hline Warehouse & $\begin{array}{l}\text { Order pick/pack accuracy for distribution to the } 18 \text { central + provincial clients is } \\
84 \% \text { for Q1, } 86 \% \text { for Q2, 88\% for Q3, and } 90 \% \text { for Q4 }\end{array}$ & $\$ 25,000$ \\
\hline Warehouse & $\begin{array}{l}\text { Order cycle time for dispatch is } 35 \text { calendar days or less for via Clássica orders to } \\
\text { the } 18 \text { central }+ \text { provincial clients }\end{array}$ & $\$ 25,000$ \\
\hline Warehouse & $\begin{array}{l}\text { Inventory accuracy in central warehouses that have implemented the MACS } \\
\text { warehouse management system is } 75 \% \text { for Q1, 78\% for Q2, } 81 \% \text { for Q3, and } \\
84 \% \text { for Q4 }\end{array}$ & $\$ 25,000$ \\
\hline \multicolumn{2}{|l|}{ Quarterly Total } & $\$ 125,000$ \\
\hline \multicolumn{2}{|c|}{ Total for Calendar Year 2013} & $\$ 500,000$ \\
\hline \multicolumn{3}{|c|}{$\begin{array}{l}\text { Abbreviations: CMAM, Central de Medicamentos e Artigos Medicos (Mozambique's central medical store); DPC, Directorate of Planning and } \\
\text { Coordination; USAID, United Sates Agency for International Development. } \\
\text { a Indicators were weighted equally. Scores for the warehouse indicators were taken in aggregate from all } 3 \text { warehouses, with targets derived from } \\
\text { aggregate warehouse performance. } \\
\text { b Product groups: HIV/AIDS, malaria, tuberculosis, essential medicines, laboratory, reproductive health, vaccines, and medical materials. }\end{array}$} \\
\hline
\end{tabular}

CMAM staff felt strongly that each performance indicator should measure the performance of an individual sector, rather than multiple sectors; staff members did not want their own results to be affected by the performance of others. This is in keeping with a lesson learned in many other RBF programs: that staff members should only be held accountable for (and thus rewarded or penalized for) something that is in their control to achieve. Otherwise, RBF may have the opposite of the intended affect: it may demotivate instead of motivate.

\section{Verification}

Verification is an essential component of RBF, validating that reported results meet the targets, time lines and other agreed-upon criteria. A robust verification process helps manage risk for all parties in an RBF agreement. Each quarter, after CMAM submitted results, a team at USAID verified those results. The team initially consisted of
2 supply chain experts and was expanded later to include 2 members of USAID's M\&E team. The verification team used a standardized checklist to ensure the integrity of the verification process.

\section{Structure of Incentive Payment}

In most RBF programs, the potential incentive payment is determined, first by considering preexisting incentives (salaries, per diems, etc.), and then by considering the level of effort required to motivate improved effort, creativity, teamwork, and, ultimately, performance. The The incentive incentive payment is not intended to reimburse, payment should for example, a health facility for the costs be high enough to associated with increasing the number of immu- be motivating but nizations it conducts. Rather, the incentive is an additional payment, calibrated to be high enough to be motivating, but not so high that it introduces perverse incentives (by, for example, focusing attention away from non-incentivized tasks). 
The mode for determining the performance payment differed somewhat from what is normally done in RBF programs. Because the FARA is a reimbursement financing mechanism, performance payments are normally determined by estimating the costs associated with completing activities and achieving targets. In the case of Mozambique, USAID considered unfunded items in CMAM's annual budget; identified those that might enable CMAM to improve its performance on the 5 performance indictors; and used the total of these items to create a budget for the performance payment (or "reimbursement" in USAID parlance). So as not to incentivize efforts related to one indicator over another, the potential reimbursement was split evenly across the indicators; that is, each of the 5 indicators was "worth" one-fifth (20\%) of the total possible payment. The Table summarizes the set of indicators, the targets, the total cost of the activities, and the agreed-to payment or reimbursement schedule.

The FARA gave CMAM complete discretion in its use of the performance payment and did not require
CMAM to provide proof of how it used the funds. In this way, the Mozambique RBF program is not unlike RBF programs targeted at health care providers, many of which allow health workers control and discretion over how to spend funds and consider such autonomy a key motivating factor in RBF. CMAM proposed a plan for allocating the funds, which was approved by the Minister of Health: 55\% were invested in the institution, with portions of this reserved for the sectors responsible for the indicators and for the GTM product category subgroups, which, as noted earlier, contribute to the planning indicator (Figure 1). The remaining, and still substantial, share of funds $(45 \%)$ was shared among all staff as personal incentives, based on an established formula that considered the rank and category of staff.

\section{FINDINGS}

During the first year of the agreement, steady progress was made on achieving the performance

FIGURE 1. CMAM Allocation of Received Funds From Results-Based Financing Program

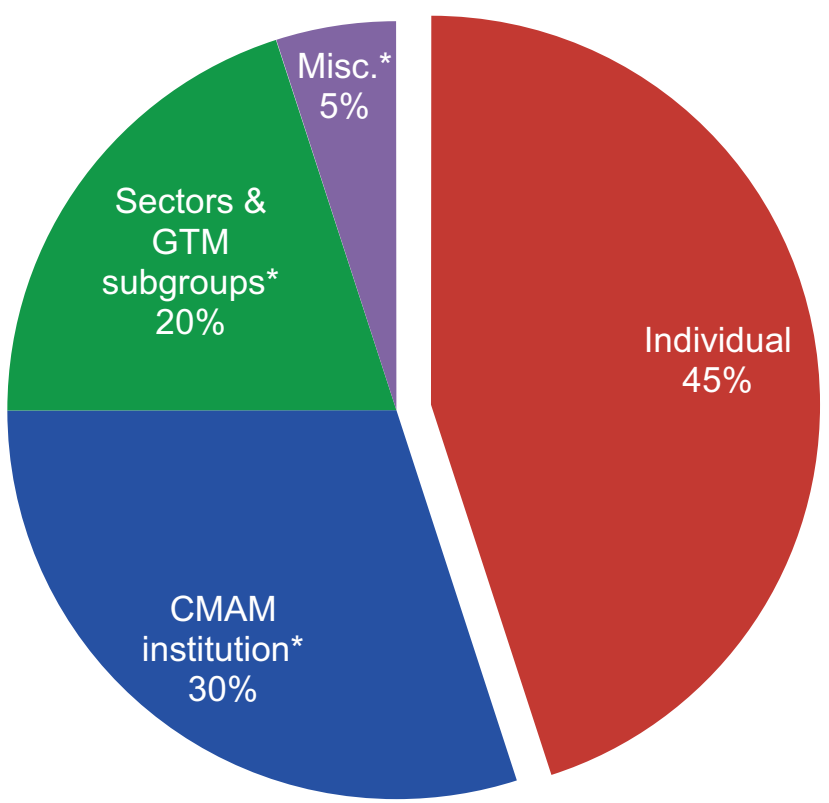

Abbreviations: CMAM, Central de Medicamentos e Artigos Medicos (Mozambique's central medical store); GTM, Grupo de Trabalho de Medicamentos (Medicines Working Group).

* Split of institutional allocation between CMAM general, sectors and GTM subgroups, and miscellaneous is approximate. 
targets, particularly for planning and distribution. Progress was not as steady, but was nonetheless positive, for the warehouse performance targets. At the time of this review, data for the fourth quarter of the first year were not yet available for all indicators.

\section{Supply Planning}

To meet the target for the supply planning indicator, each of the 8 GTM product category subgroups submitted in a timely manner a quarterly planning report-either the annual quantification report or a supply plan update-that met specified quality criteria, such as documented participation by named key stakeholders.

CMAM's baseline performance for the supply planning indicator was between 1 and 2 reports submitted each quarter (Figure 2), which, informants noted, were rarely completed in a timely or participatory manner. However, after a misstep in the first quarter, when only 3 of 8 reports were submitted and verified, the planning sector consistently achieved its targets for this indicator.

\section{Distribution Planning}

To meet the target for the distribution planning indicator, the distribution sector had to develop and submit a quarterly distribution plan within 15 days of the beginning of the planning cycle. Past performance on this indicator was inconsistent; baseline performance for the year prior (2012) and the last quarter of 2011 was as low as 9 days and as high as 27. However, the sector consistently submitted the distribution plan within the 15-day target during the first year of the RBF agreement (Figure 3).

\section{Warehouse}

Warehouse indicators, which monitored inventory management, order fulfillment, and delivery, proved more challenging. To meet the inventory accuracy indicator, a physical inventory count had to match an electronic inventory report within 1 percent margin of error, for a specific number of unique items (stock keeping units or SKUs) selected by random sampling. Maintaining accurate physical inventory and inventory records is critical to ensuring availability of commodities to fill orders and to good use of limited resources. The target for inventory accuracy was set based on historical performance and was increased incrementally each quarter throughout the year. CMAM achieved the
FIGURE 2. Supply Planning Results: Number of Supply Chain Reports Meeting Timely Submission Before (2012) and 1 Year After the Results-Based Financing Agreement Was Initiated in January 2013

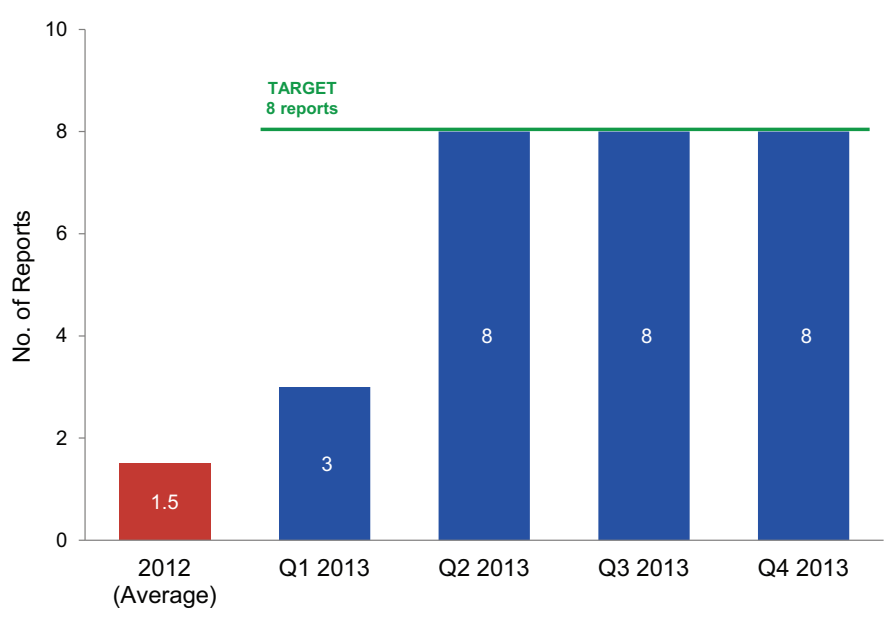

FIGURE 3. Distribution Planning Results: Number of Days From Receipt of Orders to Completion of Distribution Plan Before (2011-2012) and 1 Year After the Results-Based Financing Agreement Was Initiated in January $2013^{a}$

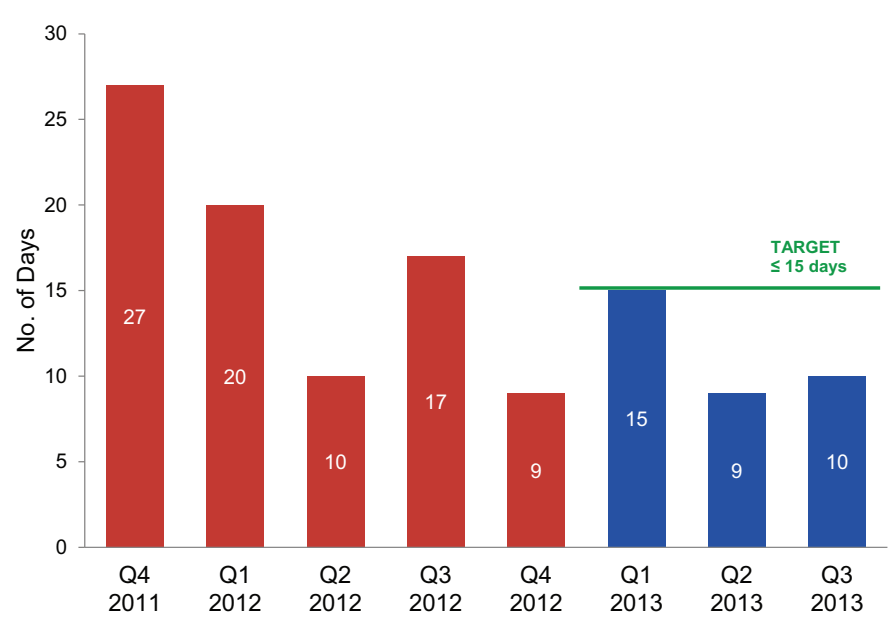

a Results for the fourth quarter of 2013 were not yet available at the time of this review. 
FIGURE 4. Inventory Accuracy Results: Percentage of Electronic Inventory Records Matching Physical Inventory Counts Before (Quarter 4 in 2012) and 1 Year After the Results-Based Financing Agreement Was Initiated in January $2013^{a}$

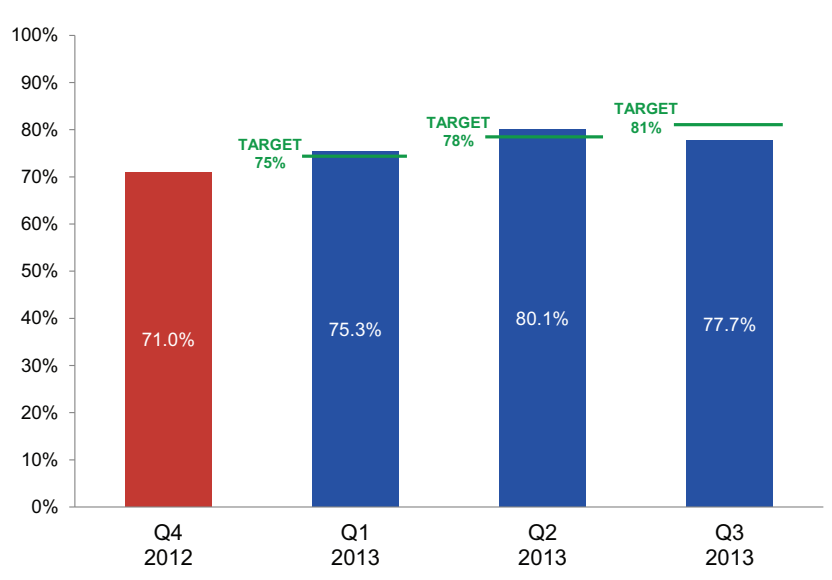

a Results for the fourth quarter of 2013 were not yet available at the time of this review. Target for the fourth quarter was set at $84 \%$.

\section{Warehouse} performance indicators proved more challenging to meet than supply and distribution planning indicators. inventory accuracy target during the first 2 quarters, but not in the third quarter. Nonetheless, measurable improvement in inventory accuracy was seen throughout the year (Figure 4).

The distribution plan drives the order fulfillment process, which is executed in the warehouse. The order pick and pack accuracy indicator was met when the number and quantity of products that were shipped to the customer matched the number and quantity approved to be shipped in the distribution plan. The target for this indicator was increased incrementally each quarter. This target was achieved only in the second quarter; however, performance continued to improve throughout the year (Figure 5). Fourth-quarter data were not available at the time of the assessment.

The dispatch cycle time indicator measured the timeliness of delivering orders to clients. This indicator was achieved when quarterly shipments were received by clients within 35 calendar days after the warehouse received the distribution plan. Baseline performance for this activity was around 42 days. Although the target was not met in the first quarter, it was met or exceeded in subsequent quarters (Figure 6).
Difficulty in meeting the warehouse targets was due, in part, to such context-specific issues as outof-service equipment; low staff levels; and Internet connectivity problems, which sometimes made it difficult to connect to the warehouse management system. Some problems may be resolved in the future if CMAM uses incentive funds to maintain equipment, but others, such as lack of staff or high staff turnover, require longer-term solutions that CMAM may not be able to control.

It is also important to note that performance improved for all warehouse indicators, even during quarters when targets were not met. This is because the warehouses were rewarded on the basis of their aggregate scores on indicators, masking variances among them. For example, in relation to the order pick and pack accuracy indicator, the target for the third quarter of 2013 was $88 \%$, whereas the aggregate score was $85.9 \%$, meaning this indicator was not met for that quarter. However, a look at their individual scores shows a large variance:

- Zimpeto: $94.4 \%$

- Beira: $65.8 \%$

- Adil: $47.8 \%$

The existing conditions at the warehouses seem to have a strong link to the individual warehouse results. Zimpeto central warehouse is the largest and best-equipped warehouse and is owned by CMAM. Located about 45 minutes outside downtown Maputo, it is well-equipped, well-organized, well-staffed, and well-lit. Zimpeto is, not unexpectedly, the best performer among the warehouses. The Adil warehouse is an hour outside Maputo in the opposite direction. Adil is a rented facility that is only partially equipped with racks, poorly lit and ventilated, and understaffed. Beira warehouse, an hour's flight north of Maputo, is similar in condition to Adil; it does not have racking or other features and, according to CMAM and its technical assistance partners, is generally the lowest performing warehouse of the three.

\section{WHAT ABOUT RBF DROVE PERFORMANCE IMPROVEMENTS?}

What about RBF spurred the improvements described above? In addition to the incentive itself, several characteristics of the performance payments appear to have motivated CMAM staff to exert extra effort and improve their performance. 


\section{Significance of Incentive Payment for Individuals}

Although the total possible FARA payment was only about $5 \%$ of the total operational investment and support CMAM receives, for individuals at CMAM, the FARA payment was significant relative to the overall compensation package of CMAM staff. In addition to their salaries, each CMAM staff member received an individual bonus each month, as well as per diem and allowances for travel. The monthly bonus had been in place since 2011, and its allocation was based on a formula that considered each staff member's job description and rank. Eligibility for the bonus depended on individual performance and attendance. FARA payments were allocated among staff based on this established formula. Although the quarterly FARA payments were smaller than the monthly bonuses, a review against the salary scale suggested that, if CMAM achieved the targets for all indicators in 1 quarter, the amount paid to each staff member for RBF in that quarter could represent as much as 1 month's salary.

\section{CMAM Discretion Over How to Spend Funds}

CMAM had full discretion over how to spend the RBF incentive payment, a crucial difference from other financing sources, and it was not required to report or reconcile back to USAID on use of the funds. Discretion and autonomy were motivating: they allowed CMAM to address small, ad hoc needs, such as purchasing distilled water for the forklift batteries or packing materials, thereby reducing CMAM's dependence on partners and providing CMAM the ability to show fiscal responsibility.

Moreover, CMAM management employed a democratic process with sector heads to agree on how the institutional portion would be spent. At the end of each quarter, CMAM management solicited a list of priority items and estimated cost from each department. Together, the colectivo (i.e., the senior management team representing each department within CMAM) decided how to spend the institutional portion.

Interestingly, although the FARA did not require CMAM to report the use of funds to USAID, after the first tranche was paid, CMAM voluntarily shared the details of how it spent the funds with USAID. After CMAM received its first incentive payment, it was able to invest in infrastructure improvements; purchase of office equipment, supplies, and materials; travel costs; and workforce environment improvements such as curtains and chairs for shared spaces.
FIGURE 5. Order Pick and Pack Accuracy Results: Percentage of Products Shipped Matching Packing List in Distribution Plan Before (Quarter 4 in 2012) and 1 Year After the Results-Based Financing Agreement Was Initiated in January 2013

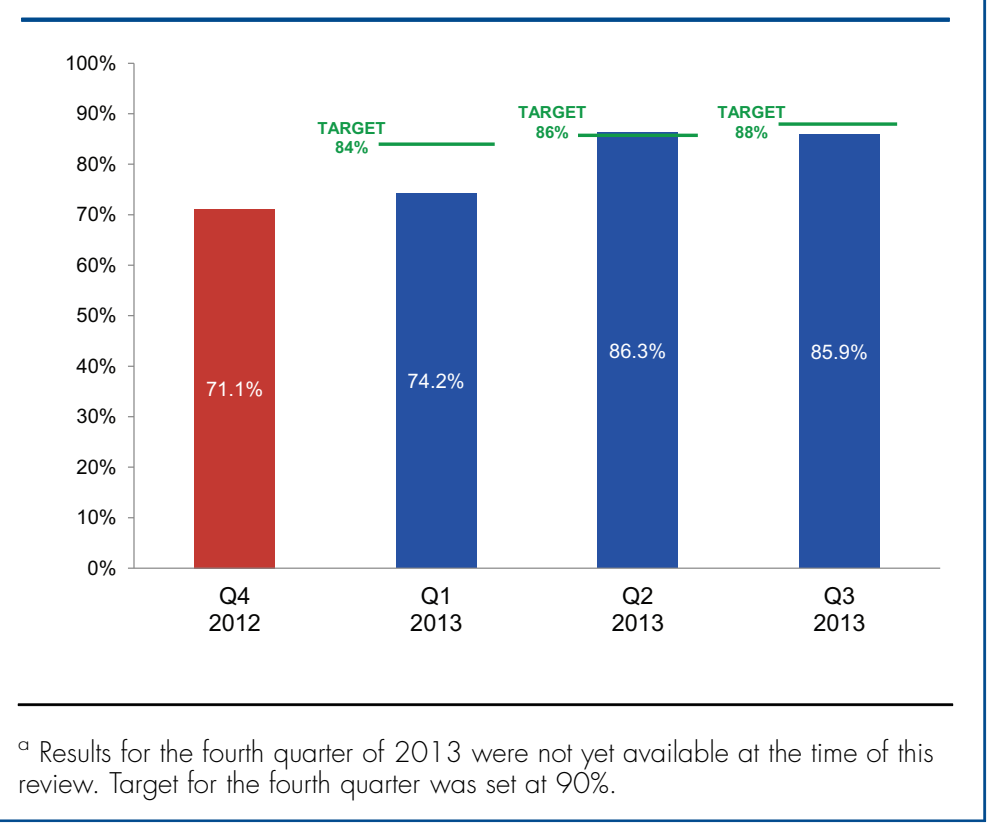

FIGURE 6. Dispatch Cycle Time: Number of Days From Receipt of Distribution Plan to Delivery of Health Commodities Before (Quarter 3-4 in 2012) and 1 Year After the Results-Based Financing Agreement Was Initiated in January 2013

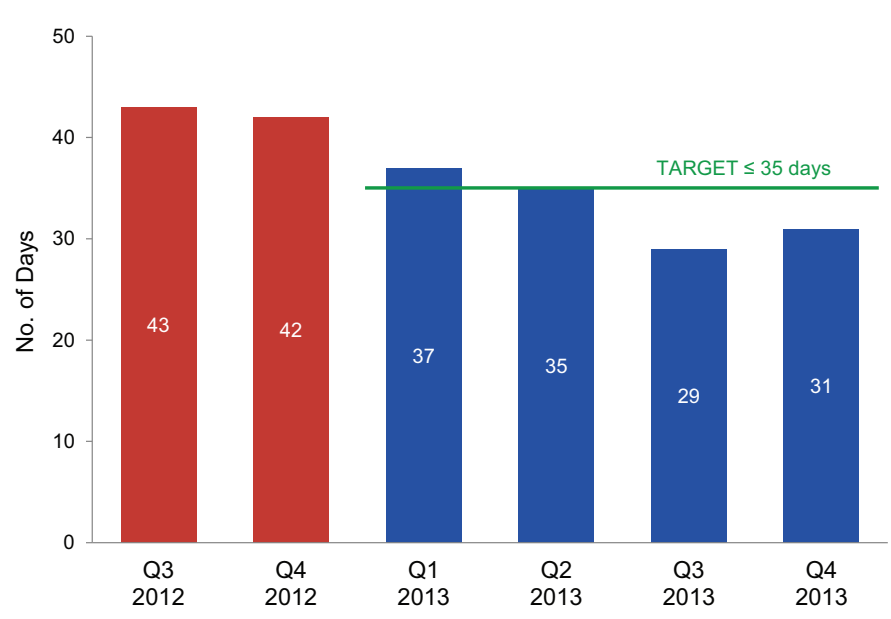




\author{
CMAM had full \\ discretion over \\ how to spend the \\ RBF payment, a \\ key factor in \\ motivating better \\ performance.
}

Staff members repeatedly praised these investments and small improvements as contributing to their workplace satisfaction and morale; they brought a sense of professional pride. Moreover, sector heads said they valued having a voice in spending decisions and seeing tangible results. The participatory process also contributed to a greater sense of transparency within the organization.

\section{Incentive Payment Was Shared With Everyone-and Depended on Everyone}

Unlike the existing monthly bonus scheme mentioned above, which is based on each individual's performance, the RBF payment was based on team performance. Although only a few sectors were directly responsible for achieving targets and reporting on the indicators, it was widely recognized that all staff had supporting roles, even if they were indirect. Interdependency to get things done was not new at CMAM, but its importance was amplified because of the FARA, where group performance translated into a tangible, personal benefit. The prospect of personal and collective gain, along with increased accountability and scrutiny of their work, seem to have created a virtuous cycle among CMAM staff members that encouraged extra effort, better attention to detail, teamwork, and collaboration.

Staff members repeatedly said they were working harder, longer hours to make sure tasks and reports were completed, adhering to processes, and using existing tools. Warehouse staff repeatedly spoke of paying more attention to detail and following standard operating procedures more closely. As an example, staff at Adil described how they began double-checking order packing accuracy: one person picked the product and another confirmed it was the correct product and quantity, even though dedicated staff members were not available for this purpose. Although a number of tools and reports were already available to CMAM staff, the data collection, measurement, and supporting documentation that were required to report performance results for the FARA encouraged their regular use.

Staff also recounted working together more closely-increasing collaboration and coordination within and among teams-and they described being proactive in seeking out data that were not forthcoming. This is important because meeting the planning and distribution indicator targets depended on the cooperation of actors from outside the responsible sectors. The head of planning at CMAM noted that, because of RBF, he was able to demand regular and timely reports from the internal technical subgroups. In the past, the groups did not regularly submit reports.

Similarly, to prepare the distribution plan before its deadline, the distribution sector relied on timely order submission from the provinces. The distribution sector head noted that during the FARA she notified provinces that if their requisitions were late, they would have lower priority during the distribution planning process. In this way, the promise of a reward spurred the distribution sector's creativity in problem solving and ability to influence changes outside the department.

\section{Prospect of Losing the Incentive}

Interestingly, the prospect of losing money also seems to have spurred improvements in performance. Although staff members had an opportunity to earn "money in our pockets," as it was described, the impact of the FARA on workplace norms was not immediate. It took the first quarter's failures and near misses to illustrate both what the staff stood to gain personally and what was possible for CMAM to receive as a whole. At the end of the first quarter, CMAM met only 2 of 5 indicators and received only $40 \%$ of the possible incentive payment (under the FARA, CMAM received zero payment for unmet targets). In the second quarter, with a better grasp of the program and what was at stake, CMAM achieved all the targets.

\section{CHALLENGES}

As with any RBF approach, unintended consequences are possible; elements meant to motivate can sometimes have the opposite effect. It is possible, for example, that jointly rewarding the warehouses had a demotivating effect. In the initial design, the high-performing warehouse(s) were, in essence, penalized by low performers. Over time, this could demotivate staff. It may also drive unintended distortions, such as gaming of the program-in other words, manipulating results for better outcomes. To address potential perverse incentives, the program may consider configuring the warehouse indicators differently, such as giving each warehouse specific targets against their own baseline.

There also appears to be some evidence that the program's approach to sharing the reward among all staff, regardless of individual contribution to 
achieving the targets, may have caused frustration. Any program where incentives are shared can potentially face the free-rider problem. Some people will inevitably work, or feel they are working, harder than others. Indeed, some CMAM staff members noted frustration that they worked overtime to achieve targets, while others in their department did not, and yet the incentive did not vary according to level of effort. This design element was deliberate: it intended to drive increased accountability within CMAM, and this did appear to be happening, as discussed previously. However, this is an area that should be monitored to minimize any negative impact on morale. In the future, it may make sense to consider including an individual performance component in the allocation formula.

\section{KEY LESSONS}

Despite challenges, overall, Mozambique's experiment with RBF for the supply chain resulted in tangible and measurable positive change. Below are key lessons related to design, implementation, and future attempts at incorporating performance incentives in public health supply chains.

\section{Program Design}

In many health systems areas, funding and know-how are not enough to spur performance improvements. RBF is intended to address the "black box" of motivation-the gap between necessary funding, inputs and training, and actual effort. As such, the goal is behavior change: increased motivation and effort. For this reason, the design of any RBF program must place motivation at the center of design decisions, which Mozambique's FARA achieved.

Among our key design lessons are:

Careful and deliberative design: Stakeholders involved in Mozambique's FAR agreement allowed the necessary time (nearly l year) to design the agreement, ensuring that all the stakeholders understood who was accountable for what. RBF will not motivate if stakeholders do not understand what they are being held accountable for.

Collaboration: Buy-in is a necessary precondition for increased motivation. The FARA design was a collaboration between USAID and CMAM, which ensured indicators were not imposed, but agreed-to as a group. The design was an iterative, consultative process with CMAM, Health Systems 20/20 (the
USAID project that preceded HFG), USAID's Supply Chain Management System (SCMS), USAID, the USAID | DELIVER PROJECT, and the World Bank, in which all participants debated and came to consensus on both the indicators and the implementation.

Specificity: The FARA clearly described each element of the agreement, including deadlines, precise indicator definitions and targets, and data sources for verification and reporting mechanisms. This ensured that the expectations and requirements were clearly defined and agreed to.

Achievable challenge: Performance indicators were the right mix of being challenging without being too difficult, and, conversely, were within CMAM's reach to achieve without being too easy. Moreover, they were relevant metrics, based on standard supply chain performance indicators; they were rigorously defined and tested during the design process.

Frequency of payment cycle: The quarterly payment cycle was frequent enough to be motivating and helped create routines among CMAM staff. Teams had renewed opportunities to meet their targets in spite of earlier failures, and quarterly deadlines were too close for staff to lose sight of them. Staff were constantly working toward new near-term deadlines and targets; quarterly payments kept the goal well within sight and reach and continuously offered the opportunity to achieve the desired results or lose the benefit.

\section{Implementation}

The design of a program is only a template- $\mathrm{a}$ theory. Impact depends on how innovations are implemented. For this, the RBF FARA was also strong, in 2 important ways.

Openness to learning and revision: RBF programs are not and should not be considered static. The flexibility to evolve as lessons were learned was an important element of the positive results of the FARA in Mozambique. For example, after testing data collection and reporting for the stock accuracy indicator in late 2012, USAID agreed to change the precise definition of the stock accuracy indicator to allow for a 1 percent margin of error in stock accuracy. Without this revision, the indicator would have been unachievable. Openness to learning and

\section{The quarterly payment cycle was frequent enough to be motivating.}


revision resulted in a relevant and achievable indicator.

The process for verification also evolvedgoing from a 2-person supply chain team to a larger team that included both supply chain and $M \& E$ experts. As the verification process was strengthened, the time from the submission by CMAM of quarterly results to the time when USAID disbursed funds was reduced from 50 days to about 30 days.

For future iterations of the agreement, stakeholders should revise the design-indicators, targets, verification-to reflect new and changing realities, while at the same time ensuring that the program remains challenging. Maintaining some core elements or core indicators may be appropriate and helpful in promoting the institutionalization of priority functions or processes, reinforcing routines and best practices.

Effective sensitization by CMAM: Effective sensitization is a foundation for any RBF program: people will not be motivated by a program they do not understand. Prior to the start of the performance period, CMAM management made sector heads responsible for communicating the program and expectations to their respective teams. No formal communication plan was set up, but the key points appeared to have been well disseminated throughout the organization, including the setting of specific targets and deadlines, that benefits would be paid only for targets that were met, and that all staff would share the benefits of meeting the targets.

\section{RECOMMENDATIONS FOR STRENGTHENING THE APPROACH}

Just as RBF
programs in
service delivery
have shifted from
a focus on
quantity of
services delivered
to improvements
in quality of care,
so too can supply
chain-RBF
programs evolve.

Strengthen incentives for quality: Many RBF programs in service delivery have evolved from rewarding health care providers for increases in the quantity of services delivered to improvements in the quality of care. RBF approaches targeted at the supply chain may see a similar trajectory. For example, in Mozambique, the quantification and supply plan indicator initially focused on the timeliness of reports; efforts then shifted to focusing on their quality.

In future iterations, incentives for quality can be strengthened. The program may consider, for example, more closely evaluating reports against quality criteria; providing feedback when a report fails to meet the criteria; and building a culture of quality improvement and data use more generally.
At CMAM, informants at the warehouses did not know either their individual warehouse performance scores or their contribution to the overall warehouse results. Access to performance data and sharing results within CMAM may further support morale and performance improvements.

Strengthen M\&E and verification to detect distortions: Verification and $M \& E$ are essential components of any RBF program, both as the means for detecting gaming and other distortions and for ensuring that the results that are paid for are real. USAID refined its approach to verification, but it could be further clarified and strengthened. As in other RBF programs, it is necessary to develop a verification process that is rigorous without being prohibitively expensive or burdensome.

In addition, CMAM's capacity to monitor performance data should be strengthened, in part to ensure that non-incentivized indicators are not being neglected. At the time of this review, CMAM's M\&E department was still relatively new and was responsible for monitoring 26 performance indicators in its M\&E plan (which includes the RBF indicators). While no evidence suggests neglect of the other indicators in Mozambique, stakeholders expressed concern about the potential for this in the future.

Aim to institutionalize the approach: Over the long term, governments, such as the Government of Mozambique, may consider institutionalizing the RBF approach-that is, rewarding verified results-both at the central level and throughout the supply chain. As the payment amount in this intervention is modest relative to CMAM's overall budget, it is conceivable to imagine the government assuming responsibility for funding in the future. However, capacity is required for refining the systems for updating indicators, setting targets, and, critically, verifying performance. Over time, with a more fully funded operational budget, it may be possible for continued performance improvements to offset the cost of maintaining such an intervention.

\footnotetext{
Acknowledgments: The authors of this report gratefully acknowledge the support that all in-country partners gave to this activity by contributing to and participating in this review. This activity was only possible with the generous time and collaboration from the management, headquarters, and warehouse staff from the Central Medical Store (CMAM). Important contributions were made by the Ministry of Health (MISAU), Supply Chain Management Systems (SCMS), the USAID I DELIVER PROJECT, DFID, UNFPA, and the World Bank. We extend special thanks to USAID/Mozambique for
} 
insight and guidance, which were instrumental in executing this activity, and to USAID for their guidance and financial support for this effort through the USAID I DELIVER PROJECT and the Health Finance and Governance Project (formerly Health Systems 20/20).

Competing Interests: None declared.

\section{REFERENCES}

1. Instituto Nacional de Estatística (INE). National data for monitoring the Millennium Development Goals. Maputo (Mozambique): INE; 2012.

2. World Bank. Maternal mortality ratio (modeled estimate, per 100,000 live births). Washington (DC): World Bank; 2013. Available from: http://data.worldbank.org/indicator/SH.STA. MMRT

3. Ministerio da Saude (MISAU) [Mozambique]; Instituto Nacional de Estatística (INE); ICF International. Moçambique inquérito demográfico e de saúde 2011 (Mozambique demographic and health survey 2011). Calverton (MD): ICF International; 2011. Co-published by MISAU and INE . Available from: http://www. dhsprogram.com/pubs/pdf/FR266/FR266.pdf

4. Instituto Nacion de Saúde (INS); Instituto Nacional de Estatística (INE). The 2009 national survey on prevalence, behavioral risks and information about HIV and AIDS in Mozambique (INSIDA). Maputo (Mozambique): INS; 2009.

5. World Bank, International Development Association (IDA). Program appraisal document on a proposed credit in the amount SDR 33 million (US $\$ 50$ million) to the Republic of Mozambique for a public financial management for results program. [Washington (DC)]: World Bank; 2014 May 30. Report Number 72624-MZ. Available from: http://www-wds.worldbank.org/ external/default/WDSContentServer/WDSP/IB/2014/06/09/ 000350881 20140609085509/Rendered/INDEX/ 726240PADOP1240ICOdisclosed06050140.txt

6. Council of Supply Chain Management Professionals (CSCMP) [Internet]. Lombard (IL): CSCMP; c2012-2016 [cited 2016 Feb 7].

\section{ADDITIONAL READINGS}

1. Bahirai E, Rosen J, Serumaga B, Stewart E. Performance-based financing: examples from public health supply chains in developing countries. Arlington (VA): USAID I DELIVER PROJECT, Task Order 4; 2012. Available from: http://deliver.jsi. com/dlvr_content/resources/allpubs/logisticsbriefs/ TechUpda_PerfBaseFina.pdf

2. Rosen JE, Serumaga B, Ndahinyuka J, Pehe N. Options for performance-based financing for public health supply chains in Rwanda: assessment report. Arlington (VA): USAID I DELIVER PROJECT, Task Order 4; 2012.

3. Rosen JE, McCord J, Owusu-Afranie D. Options for performancebased financing for public health supply chains in Ghana:
CSCMP supply chain management definitions and glossary; [about 1 screen]. Available from: http://cscmp.org/aboutcscmp/ definitions.asp

7. Eichler R, Ergo A, Serumaga B, Rosen J, Miles G, Tukai M. Options guide: performance-based incentives to strengthen public health supply chains-version 1. Bethesda (MD): Health Systems 20/20, Abt Associates Inc.; 2012. Available from: http://deliver.jsi.com/dlvr_content/resources/allpubs/ guidelines/SC_Options_Guide.pdf

8. Ministerio da Saude (MISAU) [Mozambique]. Plano de aç̧ão da CMAM (logistics plan of action). Maputo (Mozambique): MISAU; 2012.

9. Ministerio da Saude (MISAU) [Mozambique]. Plano estratégico da logística farmacêutica (strategic plan for pharmaceuticals logistics). Mozambique: MISAU; 2013.

10. Musgrove $P$. Financial and other rewards for good performance or results: a guided tour of concepts and terms and a short glossary. Washington (DC): World Bank; 2010. Available from: https:// www.rbfhealth.org/sites/rbf/files/RBFglossarylongrevised_0.pdf (2011 revision)

11. Eichler R, Levine R; Working Group on Performance-Based Incentives. Performance incentives for global health: potential and piffalls. Washington (DC): Center for Global Development; 2009. Available from: http://www.cgdev.org/sites/default/ files/9781933286297-Levine-performance-incentives.pdf

12. Morgan L, Eichler R. Performance-based incentives in SubSaharan Africa: experiences, challenges, lessons. Bethesda (MD): Health Systems 20/20, Abt Associates; 2011. Available from: http://pdf.usaid.gov/pdf_docs/pnadz294.pdf

13. United States Agency for International Development (USAID). ADS chapter 317 procurement under fixed amount reimbursement activities. Washington (DC): USAID; 2011. Available from: http://www.usaid.gov/sites/default/files/ documents/1868/317.pdf

assessment report. Arlington (VA): USAID I DELIVER PROJECT, Task Order 4 and Task Order 7; 2013.

4. Serumaga B, Rosen J, Smith K. Commercial sector performancebased financing offers lessons for public health supply chains in developing countries. Arlington (VA): USAID I DELIVER PROJECT, Task Order 4; 2012. Available from: http://deliver.jsi. com/dlvr_content/resources/allpubs/guidelines/PBFComSec. pdf

5. World Bank. Mozambique - Public Financial Management for Results Program project. Program appraisal document on a proposed grant (Report Number 72624-MZ). Washington (DC): World Bank; 2014. Available from: http://documents. worldbank. org/curated/en/2014/05/19641284/mozambique-publicfinancial-management-results-program-project

\section{Peer Reviewed}

Received: 2015 Jun 9; Accepted: 2016 Jan 20; First Published Online: 2016 Mar 2

Cite this article as: Spisak C, Morgan L, Eichler R, Rosen J, Serumaga B, Wang A. Results-based financing in Mozambique's central medical store: a review after 1 year. Glob Health Sci Pract. 2016;4(1):165-177. http://dx.doi.org/10.9745/GHSP-D-15-00173.

(c) Mukuria et al. This is an open-access article distributed under the terms of the Creative Commons Attribution License, which permits unrestricted use, distribution, and reproduction in any medium, provided the original author and source are properly cited. To view a copy of the license, visit http:// creativecommons.org/licenses/by/3.0/. When linking to this article, please use the following permanent link: http://dx.doi.org/10.9745/GHSP-D$15-00173$. 